\title{
Public perception of cold weather events as evidence for and against climate change
}

\author{
Stuart Bryce Capstick • Nicholas Frank Pidgeon
}

Received: 21 January 2013 / Accepted: 6 November 2013 /Published online: 8 January 2014

(C) The Author(s) 2013. This article is published with open access at Springerlink.com

\begin{abstract}
It has been argued that public doubts about climate change have been exacerbated by cold weather events seen as a form of disconfirming evidence for anticipated 'warming'. Although a link between perceptions of climate and weather is well-established, such assumptions have not been empirically tested. Here we show, using nationally representative data, that directly following a period of severe cold weather in the UK, three times as many people saw these events as pointing towards the reality of climate change, than as disconfirming it. This we argue was a consequence of these cold winters being incorporated into a conceptualisation of extreme or 'unnatural' weather resulting from climate change. We also show that the way in which people interpret cold weather is associated with levels of pre-existing scepticism about climate change, which is in turn related to more general worldviews. Drawing attention to 'extreme' weather as a consequence of climate change can be a useful communication device, however this is problematic in the case of seasonal cold.
\end{abstract}

\section{Introduction}

Recent years have seen declines in public acceptance of, and concern about, climate change from previously high levels observed following the publication of the fourth IPCC assessment report (Smith and Leiserowitz 2012; Pidgeon 2012). Although some data now suggest a partial rebound (Borick and Rabe 2012; Leiserowitz et al. 2012), the prevailing downwards shift in public opinion was particularly striking in the late 2000's, a period coinciding with unusually cold winters in Europe and the United States. In the UK these included the coldest winter (2009/2010) for 30 years and the second coldest December (2010) for 350 years (Blunden et al. 2011).

Some commentators have suggested these phenomena were related: in essence, that experience of extreme cold weather was interpreted by people as a form of evidence disconfirming a supposed 'warming' effect. The Daily Telegraph (January 6th, 2010) for example quotes the atmospheric scientist Steve Dorling noting that "[i]t's no surprise that people look out of their window at the snow and find it hard to rationalise what's going on with

Electronic supplementary material The online version of this article (doi:10.1007/s10584-013-1003-1) contains supplementary material, which is available to authorized users.

S. B. Capstick $(\bowtie) \cdot$ N. F. Pidgeon

Cardiff University, Cardiff, UK

e-mail: capsticksb@Cardiff.ac.uk 
the longer term trend". Writing in Nature Climate Change, Perkins (2010) similarly suggests "[t]he icy conditions of winter 2009/2010 in Europe caused some public confusion over the extent to which the climate is changing"; Moser and Dilling (2011:161) likewise remark that "[a]midst... a cooler, less extreme year in many regions across the globe, public concern about global warming dropped significantly". Even COP15's limited success was attributed to it being "absurd to make the case for global warming at a time of incredible cold. The weather was why people struggled" (Knight 2012:36). More generally, a number of studies have suggested that public belief and concern about climate change varies in line with local temperature and temperature change - both actual and perceived (Akerlof et al. 2013; Lorenzoni and Pidgeon 2006; Joireman et al. 2010; Li et al. 2011; Howe et al. 2013). In the UK, change in the weather is referred to more frequently than any other impact as an anticipated consequence of climate change (Shuckburgh et al. 2012; Whitmarsh 2009; Lorenzoni et al. 2006). In the USA, a majority perceive that climate change has exacerbated extreme weather events (Leiserowitz et al. 2012). An association between climate change and temperature increase or 'heat' is also frequently reported (Whitmarsh 2009; Smith and Leiserowitz 2012).

A reliance on personal experiences such as with the weather may help anchor the abstract nature of climate change to the familiar and concrete (Smith and Joffe 2013). Perceived personal experience of climate consequences can also bring about acceptance of climate change as a genuine concern (Myers et al. 2013; Spence et al. 2011). Consistent with work on the perception of environmental risks more generally, is the idea that people apply the evidence of their own eyes to draw conclusions about abstract phenomena (Horlick-Jones et al. 2007). This may at times lead to higher trust being placed in direct, personal experiences than in secondary information sources (e.g. through the media) (Bickerstaff and Walker 2001).

Given the salience of a climate-weather connection in public perceptions and the increase in doubts about climate change concurrent with severe cold weather, it is important to ask to what extent a corresponding causal connection was made by people. Were such a link to be empirically established, this might be considered evidence of a general misreading of the meaning of such discrete weather events, and point to the need for further refinement in the making of a distinction between 'weather' and 'climate' (cf. Reynolds et al. 2010). There is however the alternative possibility that these same events were interpreted not as an absence of climatic warming, but as a sign of extreme weather caused by climate change, as have other studies found that flooding (Spence et al. 2011) and raised temperatures and hurricanes (Leiserowitz et al. 2012; Borick and Rabe 2010) have been construed. We therefore examine two alternative possibilities concerning the interpretation of cold weather events: that they were seen either as evidence for, or evidence against, the reality of climate change.

Having identified the prevalence of different interpretations of cold weather events, we next assess whether these are associated with pre-existing attitudes. A substantial psychological literature suggests that people with opposing prior attitudes process the same ambiguous evidence in different ways, an effect termed 'biased assimilation' (Lord and Taylor 2009). This has been demonstrated in the context of climate change by experimental work examining individuals' evaluation of conflicting arguments in media articles (Corner et al. 2012) and by longitudinal analysis suggesting those already engaged with climate change draw on personal experiences to support pre-existing views (Myers et al. 2013).

In the present study we test whether differences in respondents' climate change scepticism are related to interpretations made about the weather in the context of climate change. Here we 
consider climate change scepticism in line with the approach outlined by Poortinga et al. (2011) and Rahmstorf (2004) — as constituting doubts about the reality, human causation, and severity of climate change, termed 'trend', 'attribution', and 'impact' scepticism respectively' where we refer subsequently to 'climate change scepticism' or 'scepticism', it is according to this framework.

We also examine whether this climate change scepticism is itself underpinned by more general worldviews. Previous studies have shown that climate change scepticism is related to underlying values and political ideology as well as sociodemographic factors (Poortinga et al. 2011; Whitmarsh 2011). In the present study, we draw on cultural theory, which proposes that risks are selectively emphasised or suppressed depending on one's preferences for different types of social control and organisation (Wildavsky and Dake 1990). According to this theory, people who subscribe to more individualistic ways of life exhibit lower affiliation with society as a collective whole, whereas those subscribing to a more egalitarian outlook see collective organisation and problem-solving as socially desirable, especially for global-scale problems such as climate change. For individualists, nature is viewed as resilient and climate change considered unproblematic precisely because this position aligns with their preferred worldview, in which people are free to act autonomously with few restrictions on personal and economic activity. By contrast, the egalitarian worldview, in which social equity is paramount and common effort is valued, is commensurate with a view of nature as fragile and ephemeral, with climate change seen as dangerous and requiring action (Thompson 2003; Steg and Sievers 2000). Because cultural worldviews constitute a generalised outlook, we propose a mechanism whereby these operate at the first stage of a causal chain, influencing the more specific attitudes of climate change scepticism. We predict that scepticism will in turn be connected to the interpretation of cold weather events - either as confirming or negating the existence of climate change.

We also consider the wider context of public discourse through examining media reporting at the time the research was conducted. The mass media have been shown to exert important influence upon public understanding of climate change (Carvalho 2010). An analysis of media representations thus enables us to consider the wider social context that may have played a part in shaping individuals' interpretations of cold weather at the time of the research.

\section{Method}

\subsection{Survey instrument and public participants}

The study utilises items which were included within a survey of public perceptions of climate change in the UK (for further details see Capstick 2012). The wider survey within which the items considered in the present study were embedded covered a range of themes concerned with people's interpretation of climate change. In the first part of this survey, respondents were asked to indicate the perceived importance of each of a range of societal and socio-technical issues including climate change. They were then asked their level of concern about climate change, and answered open-ended questions about immediate associations made with climate

\footnotetext{
${ }^{1}$ Our treatment of climate change scepticism is one of several possible approaches. For example: Smith and Leiserowitz (2012) consider climate change scepticism in terms of the affective imagery people associate with climate change, incorporating doubts about honesty of conduct in science and perceptions of media hype; and Whitmarsh (2011) has treated scepticism as a multi-dimensional construct which includes perspectives on the scientific evidence base and media portrayal of climate change, as well as personal uncertainty.
} 
change. Respondents subsequently completed a battery of 52 closed-ended items covering aspects such as self-reported knowledge about climate change, perceptions of scientific consensus, and perceived self-efficacy and collective efficacy in responding to climate change.

Within the battery of 52 items, four items were used to measure the two competing interpretations of the weather considered by the present study. One item pair framed the cold weather (either as a single winter contextualised to late 2010, or as a 'pattern' of cold winters) as evidence against climate change (Cronbach's $\alpha=.89$ ). The other item pair was similarly constructed, but framed the cold weather as evidence for climate change (Cronbach's $\alpha=.87$ ). The wording used for these items is given in Table 1. Each was measured by responses along a five-point scale from 'strongly disagree' to 'strongly agree'. Also within the battery of 52 items, six items were used to measure climate change scepticism, two each corresponding to trend, attribution, and impact scepticism, as conceptualised by Rahmstorf (2004) and Poortinga et al. (2011). By this framework, 'trend scepticism' refers to doubts that climate change is happening at all, 'attribution scepticism' refers to doubts about an anthropogenic component, and 'impact scepticism' refers to doubts about the severity of climate impacts. The six scepticism items are given in Table 1; again, respondents were asked to indicate their level of agreement or disagreement with each. These items together formed a reliable index (Cronbach's $\alpha=.90$ ). The ten items gauging respondents' interpretation of cold weather events and their level of climate change scepticism were presented in a randomised order as part of the larger set of 52 items.

Having answered the questions described above, respondents next indicated the length of time they had personally been aware of climate change, ${ }^{2}$ and were asked to indicate any reasons for changes in their views over this time. This was done via the open-ended question: "If your views have changed, please tell us why this might be". Responses to this question were independently coded by two researchers to examine for the incidence of arguments that cold weather events constituted evidence for/against climate change. Further detail regarding inter-observer reliability for this coding is given in Section 3.1.3.

Respondents next indicated their level of agreement or disagreement with six items designed to measure preferences for different forms of social organisation, as conceptualised within the cultural theory framework. Three 'individualism' and three 'egalitarianism' cultural worldview items were adapted from previous work (Leiserowitz et al. 2010; Rippl 2002); the items used are shown in Table 1. Principal components analysis confirmed the two-factor structure of these items, with factor scores used in subsequent analyses.

Survey respondents $(n=500)$ were drawn from across the UK via an online respondent panel maintained by a market research company. Quota sampling (Brick 2011) was used to ensure the sample was representative according to gender and age bands, based on 2001 UK Census estimates. Further details concerning the profile of the sample obtained are given in Table S1 (supplemental information).

\subsection{Content analysis of media articles}

A deductive approach to content analysis (Matthes and Kohring 2008) was used to examine media sources for the presence of particular framings concerning the links between cold

\footnotetext{
${ }^{2}$ This question was contextualised through being preceded by the following information: "An important part of the research project is to understand how people's views may have changed over time. First, please try to think back over the time period that you personally have been aware of climate change, in any sense".
} 
Table 1 Survey constructs and item wording

Construct Wording

Weather interpretation

Weather as evidence against climate change (Cronbach's $\alpha=.89$ )

Weather as evidence for climate change (Cronbach's $\alpha=.87$ )

Scepticism index

(Cronbach's $\alpha=.90$ )

Trend scepticism

Attribution scepticism

Impact scepticism

Cultural worldview

Factor 1:

Egalitarianism

Factor 2:

Individualism
The cold winter which occurred during late 2010, suggests that climate change may not be happening

The pattern of cold winters in recent years, suggests that climate change may not be happening

The cold winter which occurred during late 2010, suggests that climate change may now be a reality

The pattern of cold winters in recent years, suggests that climate change may now be a reality

There is too much conflicting evidence about climate change to know whether it is actually happening

The evidence for climate change is unreliable

Current climate change is part of a pattern that has been going on for millions of years

Climate change is just a natural fluctuation in Earth's temperatures

The seriousness of climate change is exaggerated

The effects of climate change are likely to be catastrophic (reversecoded)

Discrimination against minorities is still a very serious problem in our society

The world would be a better place if its wealth were divided equally among nations

In my ideal society, all basic needs (food, housing, education, health care) would be guaranteed by the government for everyone

People should be allowed to make as much money as they can for themselves, even if others are not able to

When I have problems, I try to solve them on my own

If the government spent less time trying to fix everybody's problems, we'd all be a lot better off

weather and climate change. We sought to identify among UK newspaper articles those in which (i) cold weather was presented as commensurate with (e.g. as 'evidence for') the presence of climate change, or (ii) cold weather was presented as inconsistent with (e.g. as 'evidence against') the presence of climate change. In a number of cases, articles consider such conceptual links without alluding to a particular position and so we also include a category to reflect this. The coding of newspaper articles was carried out by two researchers independently. Further detail regarding inter-observer reliability is given in Section 3.2.

We examined both tabloid and broadsheet newspaper articles to encompass media representations across a broad readership and range of political positions; see Table S2 (supplemental information) for sources used.

Using the Lexis Nexis database, a Boolean search for the terms 'winter' and 'climate change', and/or 'snow' and 'climate change' was used to search for articles (including letters to the Editor) for the purposes of the study. The search was restricted to the period 1st December 2010 to 15 th February 2011, corresponding to the winter preceding the administration of the public survey. 


\section{Analysis and results}

3.1 Public perceptions of cold weather and climate change

\subsubsection{Data distributions}

The ratio of those viewing the pattern of cold winters as evidence for as opposed to against climate change was approximately 3:1. Across the sample of 500 respondents, $16.1 \%$ agreed or strongly agreed that this suggested climate change may not be happening $(50.0 \%$ disagreed or strongly disagreed) whereas $45.0 \%$ agreed or strongly agreed that this pointed to climate change being a reality (19.7\% disagreed or strongly disagreed). Likewise, across the sample $13.6 \%$ agreed or strongly agreed that the cold winter of late 2010 suggested climate change may not be happening (49.3\% disagreed or strongly disagreed), whereas $38.5 \%$ agreed or strongly agreed that the 2010 cold winter pointed towards climate change being a reality (21.8\% disagreed or strongly disagreed). Remaining responses were 'neither agree nor disagree' or 'don't know/no opinion'.

Across the sample as a whole, approximately $4 \%$ of respondents gave answers which could be interpreted as inconsistent, agreeing or strongly agreeing that cold winter(s) constituted both evidence for and against climate change. We include these data in our analyses as, whilst inconsistent, for some they may reflect a genuinely ambivalent position concerning the interpretation of weather.

Descriptive statistics for all weather interpretation items are shown in Table S3 (supplemental information) and presented in graphical form for the 'cold winter of late 2010' items in Figure S1 (supplemental information).

The mean climate change scepticism score (itself calculated as the mean of the six items) was $3.14(\mathrm{SD}=.91)$; scores ranged from 1 to 5 , with higher scores representing higher levels of climate change scepticism. Response distributions cross-tabulated by degree of climate change scepticism are additionally revealing. In Figs. 1 and 2 we show responses to items framing the cold winter of 2010 as evidence for/against climate change, against three terciles

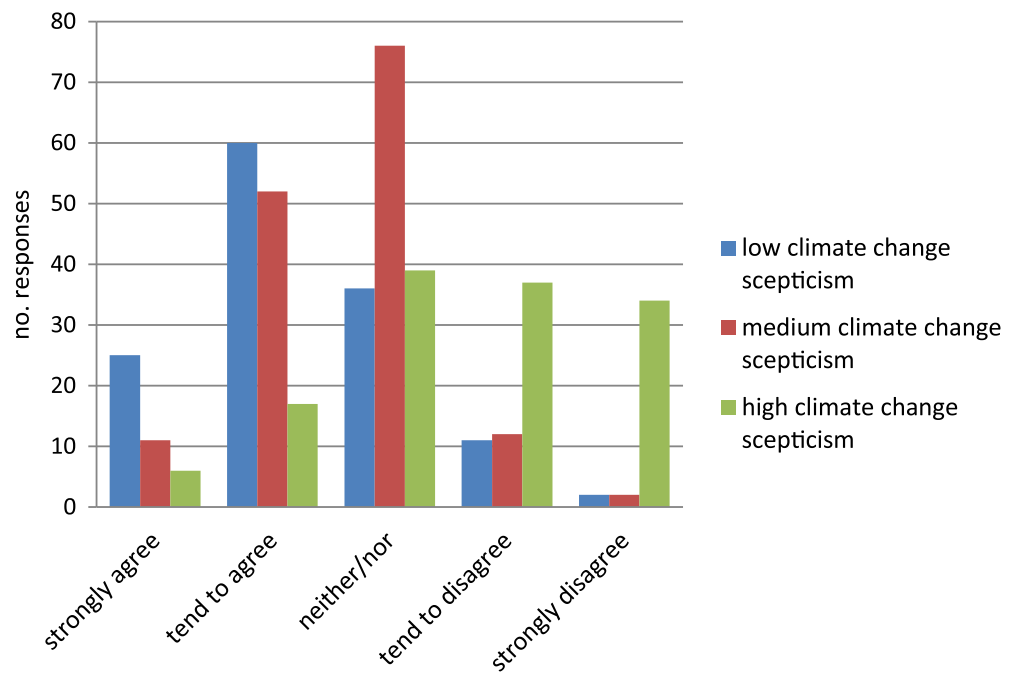

Fig. 1 Response distributions: winter 2010 is evidence for climate change 


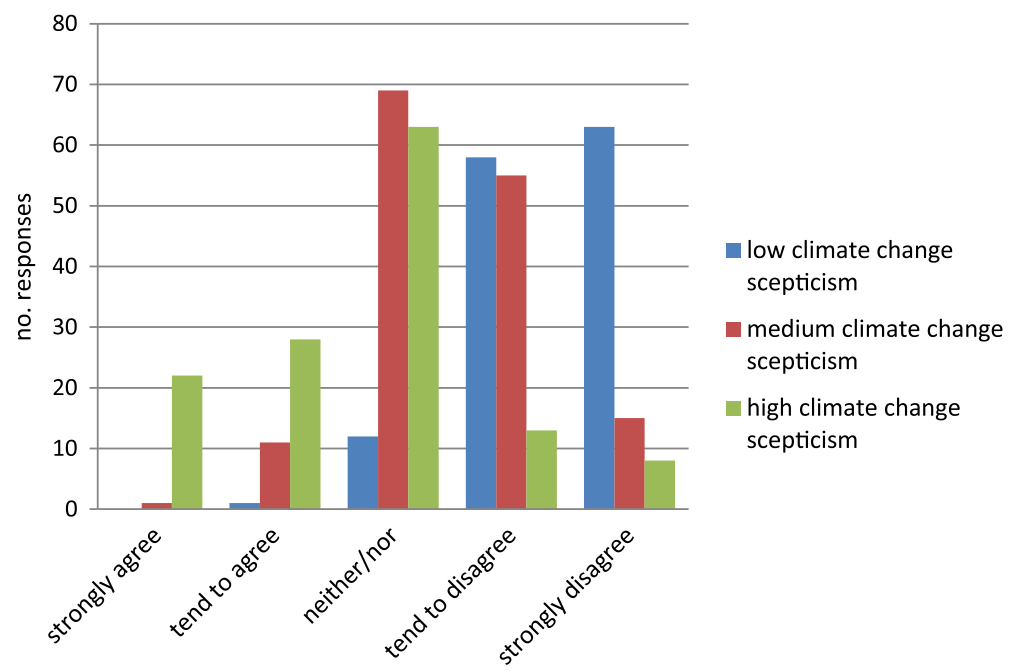

Fig. 2 Response distributions: winter 2010 is evidence against climate change

corresponding to low, medium and high climate change scepticism. The mean climate change scepticism scores and standard deviations of these terciles were as follows: low scepticism $(\overline{\mathrm{x}}=2.11, \mathrm{SD}=.44)$, medium scepticism $(\overline{\mathrm{x}}=3.13, \mathrm{SD}=.23)$, high scepticism $(\overline{\mathrm{x}}=4.18$, $\mathrm{SD}=.45)$.

Respondents in the upper tercile (high climate change scepticism) were more inclined to see the winter of late 2010 as evidence against climate change than were respondents in the medium or low climate change scepticism groups (Mann-Whitney $U=5681, p<.001$, and $U=$ $1821, p<.001$ respectively) and less inclined to see it as evidence for climate change $(U=5215$, $p<.001$, and $U=3593, p<.001$ respectively).

The shape of these distributions also shows that a non-committal central position is a more common response of 'sceptics', whereas for 'non-sceptics' the distributions are more markedly skewed: it is 'non-sceptics' who are more willing to assert a position regarding how cold weather relates to climate change.

\subsubsection{Mediation analysis}

We conducted mediation analysis using customised SPSS syntax permitting the estimation of direct and indirect effects of multiple causal variables (Hayes 2013). The outcome variable was formed of the two items framing cold winter(s) as evidence against climate change, with the climate change scepticism index treated as a mediator variable and the two worldview factors treated as independent variables. As shown in Fig. 3, climate change scepticism was a significant and powerful predictor of weather interpretations in the model $(b=.70, t=16.44$, $p<.001$ ). In the model constructed, cultural worldviews did not directly predict weather interpretations (outer arrows in Fig. 3). However, worldviews directly predicted levels of climate change scepticism (for egalitarianism, $b=-.22, t=-4.99, p<.001$; for individualism, $b=.42, t=9.47, p<.001$ ), and exerted an indirect effect upon weather interpretations through climate change scepticism ( $95 \%$ confidence intervals for indirect effects of egalitarianism are $-.23,-.09$ and for individualism are $.23, .37)$. The full model explains $49 \%$ of variance in weather interpretation $\left(R^{2}=.49, F(6,390)=63.41, p<.001\right)$. 


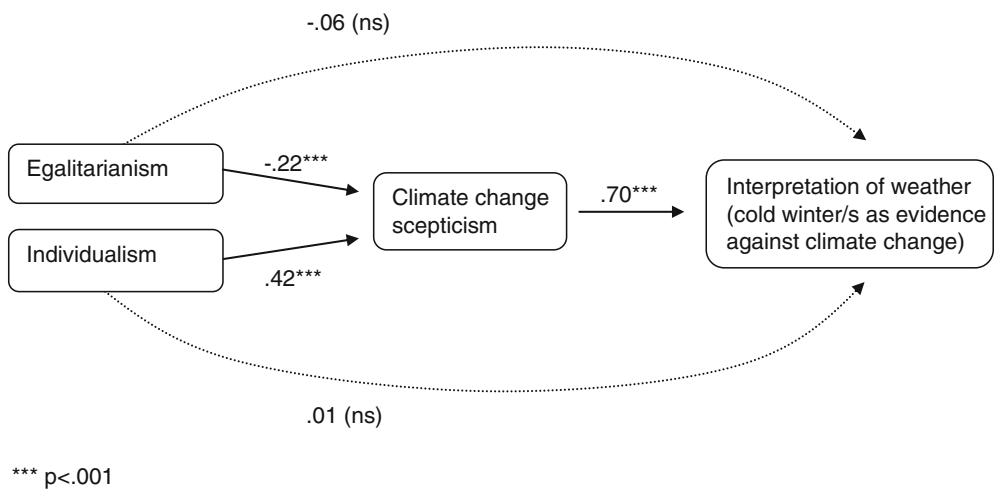

Fig. 3 Effects of cultural worldview and climate change scepticism on weather interpretation

Bootstrapping (10,000 samples) is incorporated in the mediation analysis, to comply with the assumption of normally distributed data where calculating indirect effects. Sociodemographic variables (age, gender, level of qualifications) are included in the analysis as covariates, although only small and statistically non-significant effects were obtained and so these are not reported separately. $Z$-scores for all variables were used in analyses meaning that coefficients reported are standardised for direct effects. Missing values were moderately high at between $0 \%$ and $15 \%$ for each factor used in the analyses; Little's MCAR test however was non-significant (indicating missing data is randomly distributed) and therefore listwise deletion was applied.

\subsubsection{Self-reported changes in views}

118 respondents volunteered information concerning changes in their views over the time period they had been aware of climate change (a further 38 answered that their views had not changed, while the majority, $n=344$, did not volunteer any response).

Of the 118 responses providing a reason for changed views, 29 of these $(25 \%)$ were concerned with changes to the weather and/or seasonality. Of this sub-sample, seven responses did not express a clear position (e.g. simply responding "changes in weather"). Only one respondent expressed the view that the weather provided evidence against the veracity of climate change, namely:

We have always been told that climate change is about Global Warming, but Britain has just been through two very cold winters in a row, so on the evidence available Global

Warming does not seem to be happening.

Whilst not contending that cold weather events directly constituted evidence against climate change, a further four respondents presented arguments consistent with the view that these were not valid evidence for the presence of climate change, as in the following response:

There has been no real evidence that climate change is due to people and the way they use energy etc. We have always had cold winters and not very warm summers.

By contrast, 17 respondents expressed a viewpoint consistent with the position that the weather provides evidence for the veracity of climate change - although in most cases these were with reference to altered or more extreme weather, rather than cold weather per se. A selection of these responses is shown in Figure S2 (supplemental information). 
The open-ended survey text was independently coded by two researchers. Inter-observer reliability was high overall: Cohen's kappa $>.9$, calculated for three response categories (reason given for changed views vs. no reason given, weather-related responses vs. nonweather related responses, 'evidence for' vs. 'evidence against' responses) with a consensus subsequently reached between the two coders for items where there was not initial agreement.

Those responses giving reasons for changes in views but which were not concerned with changes to the weather covered such topics as perceived uncertainty among climate scientists (e.g. "not enough agreement among scientists"), reflections on the relevance of climate change in light of personal circumstances (e.g. "more worried because I now have a child"), or perspectives on wider societal contexts (e.g. "too much rhetoric from those that have selfinterest as their reason for voicing").

\subsection{Media reporting of cold weather and climate change}

Of 132 articles retrieved from the 1st December 2010 to 15th February 2011 time period using the search terms, 41 directly commented upon the links between cold weather and climate change. Of these, 18 included text framing the cold weather as commensurate with climate change, 18 framed the cold weather as being inconsistent with climate change, and five presented an indeterminate position (e.g. presenting arguments for both). Table 2 gives illustrative examples of headlines and article text arising from the content analysis. Table S2 (supplemental information) provides further breakdown of article coding by media source.

In the case of articles coded as framing cold weather as commensurate with climate change, this in places portrayed the cold weather as a direct consequence of, or evidence for, climate change. In other places, the implication was that the cold weather occurred in spite of overall

Table 2 Connections made between cold weather and climate change in the UK press

\begin{tabular}{|c|c|}
\hline Weather-climate framing & Example text or headline (source) \\
\hline \multirow[t]{3}{*}{$\begin{array}{l}\text { Cold weather commensurate with } \\
\text { climate change }(n=18)\end{array}$} & $\begin{array}{l}\text { "That snow outside is what global warming looks like" } \\
\text { (The Guardian, December 21st 2010) }\end{array}$ \\
\hline & $\begin{array}{l}\text { WHY GLOBAL WARMING WILL FREEZE BRITAIN } \\
\text { (The Daily Telegraph, January 26th 2011) }\end{array}$ \\
\hline & $\begin{array}{l}\text { "Winters like last year's could become the norm as faster melting ice } \\
\text { threatens dramatic climate change" } \\
\text { (The Mirror, January 26th 2011) }\end{array}$ \\
\hline \multirow[t]{3}{*}{$\begin{array}{l}\text { Cold weather inconsistent with } \\
\text { climate change }(n=18)\end{array}$} & $\begin{array}{l}\text { THE TRUTH IS GLOBAL WARMING HAS HALTED } \\
\text { (Mail on Sunday, December 5th 2010) }\end{array}$ \\
\hline & $\begin{array}{l}\text { "[A]s another bitter winter sets in, the claims of imminent environmental } \\
\text { doom are exposed as nothing more than manipulative propaganda" } \\
\text { (The Express, December 9th 2010) }\end{array}$ \\
\hline & $\begin{array}{l}\text { "[W]ith no 'global warming' since } 1998 \text { [and] a succession of bitter } \\
\text { winters... it is only a matter of time before the AGW industry } \\
\text { collapses" } \\
\text { (The Daily Telegraph, January 24th 2011) }\end{array}$ \\
\hline Indeterminate position $(n=5)$ & $\begin{array}{l}\text { "[T]here is an overwhelming temptation to point a finger at the nearest } \\
\text { climate scientist and roar "where's your global warming now?" [...] } \\
\text { However, the Journal of Geophysical Research has found that the cold } \\
\text { snap... may be the result of global warming, rather than evidence to } \\
\text { the contrary" } \\
\text { (The Sunday Times, December 26th 2010) }\end{array}$ \\
\hline
\end{tabular}


warming. In the case of articles coded as framing cold weather as inconsistent with climate change, the dominant portrayal was that the cold weather in some way weakened the case for climate change (i.e. was a form of 'evidence against').

The number of articles placed in each category is derived from independent coding by two researchers. Following the extraction of the 41 relevant articles, full agreement was reached on the 36 articles framing climate change either as commensurate or inconsistent with climate change. Following further consideration of coders' notes concerning the remaining five articles, these were assigned an 'indeterminate' category wherein either a clear link was not made, or reference was made to both ways of relating the cold weather to climate change.

\section{Discussion}

The occurrence of cold winters in northern Europe in the late 2000's might or might not have been connected to climate change (Overland et al. 2011; Guirguis et al. 2011). Here we argue that the conclusions which could be drawn by lay individuals about these weather events varied widely, but were more often of the confirmatory variety. This is likely to be because exceptionally cold winters - where ascribed a meaning at all — tended to be understood by many respondents in terms of climate change leading to weather which is extreme, strange, bizarre or different from expected (Smith and Joffe 2013). Whilst it may seem counter-intuitive that cold weather would be integrated in people's perceptions of climate change in this manner, this may be indicative of a general shift in the use of terminology (in the UK at least) from 'global warming' to 'climate change'. As previous research has shown, the former phrase tends to be more closely associated with temperature rise whereas the latter tends to be more associated with 'change' to the weather (Whitmarsh 2009). Our findings are also in line with recent research that finds similar connections are made by people with a range of other weather extremes - including flooding, drought, high summer temperatures and changes to seasons (Leiserowitz et al. 2012; Smith and Joffe 2013).

The findings of the present study likely also reflect a recognition that, for some respondents, isolated cold weather events have limited implications in themselves, or can simply be considered anomalies (cf. Cattiaux et al. 2010). It is noteworthy that a large proportion (around one third) of respondents were not willing to align with the positional statements (for or against) in each case: this is arguably the most appropriate current response to the items as presented, given the difficulty in attributing discrete weather events to climate change. By contrast, there exists only a small minority of people who consider that cold weather disconfirms the idea that climate change is happening.

These results lead us to suggest that members of the public are in possession of a more nuanced understanding of the relationship between weather and climate change than has perhaps been assumed in the past - for example in assertions that people unduly 'conflate' weather and climate (Bostrom and Lashof 2007). Whilst the technicalities of the distinction may well elude most people ${ }^{3}$ our findings do suggest that many hold mental models which go beyond a simple association between climate change and raised temperatures as a whole.

The present study additionally presents evidence that, during the winter months immediately preceding the public perceptions research, cold weather events were framed in the media both in terms of evidence contrary to the veracity of climate change, and as evidence of its

\footnotetext{
${ }^{3}$ For example, the IPCC refers in its glossary of terms to climate change as "a change in the state of the climate that can be identified... by changes in the mean and/or the variability of its properties, and that persists for an extended period, typically decades or longer".
} 
manifestation. Previous studies have shown that the media are key sources of information for people about climate change (Carvalho 2010) and thus it seems likely that, as well as cold weather events in themselves offering the potential for disparate interpretations, the ways in which these events were presented in the media formed part of a wider public discourse around the meaning of the cold weather at this time.

The study finds that the way in which the weather is interpreted by members of the public is closely related to ideological differences. That identical occurrences (cold winter/s) may be used to draw contradictory conclusions, and that these conclusions themselves are related to pre-existing positions, is likely an expression of what has been termed 'motivated reasoning' or 'biased assimilation' (cf. Kunda 1990; Lord and Taylor 2009). This entails the appraisal of evidence in ways that validate pre-existing beliefs and identity, a phenomenon which has recently been linked to climate change perceptions (Whitmarsh 2011; Corner et al. 2012). Goebbert et al. (2012) have suggested that because temperature change in particular has become a politicised matter in the context of climate change, people's interpretations of the weather are likely to be subject to influence via their worldviews. In this sense, cold weather may be considered but one example of a range of information which can be used by lay individuals to draw conclusions about climate change. Yet because the weather is able to be directly experienced by all and is strongly associated conceptually with climate change, this makes its use as a class of informal evidence especially important to consider.

In the present study we find that 'non-sceptics' are as inclined to attribute a meaning to cold weather events as are 'sceptics' (perhaps more so). This points to the way 'evidence' is subject to processes of interpretation among those who do not in fact doubt climate change, as well as by those who do - a phenomenon which has been somewhat overlooked in the literature thus far. Our findings are in line with previous research suggesting that attitudinal certainty is more pronounced among those who are not sceptical about climate change (Poortinga et al. 2011). This said, other work has by contrast found that components of climate change scepticism are associated with particularly strong negative affect, indicating pronounced strength of feeling among those who express doubts about climate change (Smith and Leiserowitz 2012).

\subsection{Implications for communication}

A challenge for those interested in promoting public engagement, is that climate change has been considered a phenomenon characterised by 'psychological distance' (Spence et al. 2012) - perceived as affecting other places, persons and time periods, and associated with uncertainty. As such, some researchers have suggested that greater attention be drawn to the personally-relevant aspects of climate change: Lorenzoni and Pidgeon (2006) for example argue that climate change be situated in people's immediate locality so as to heighten saliency. Spence et al. (2011) indeed propose that deliberately highlighting the links between local weather events and climate change can help to generate greater public engagement - assuming that is one's aim.

In line with this research, one conclusion that could be drawn from the present study might be to consider drawing conceptual links between climate change and events such as the UK cold winter of 2010-2011 for the purposes of communication. Whilst drawing attention to the consequences of climate change can lead to it being perceived as a more proximal and tangible phenomenon, in the case of cold weather events such as those of 2010-2011 this should however be approached with great caution. Projections for the UK are in fact for milder winters - although with more extreme weather events such as summer heatwaves and flooding anticipated (Defra 2012); while, overall, a decrease in extreme cold weather is projected worldwide (Coumou and Rahmstorf 2012). In addition, it is problematic to conceive of discrete events as being 'caused' by anthropogenic climate change (Trenberth 2012). 
The most appropriate message to convey may instead be that extreme cold winters can still be expected to occur, and are not inconsistent with rising global mean temperatures (Cattiaux et al. 2010). At the same time, models do point to more frequent and intense extreme precipitation events, including in northern latitudes during winter (Trenberth 2012). The heavy snowfalls experienced during 2010-2011, are thus in some senses illustrative of the types of consequences which may be expected more often in future.

Given the potential communication advantages - but logical difficulties - of making connections between discrete weather events and concrete manifestations of climate change, further research would be valuable to understand how this could be most appropriately be done. One way this could be achieved is through the development of materials which are aligned with the current state of scientific knowledge in this area, followed by the subsequent testing and appraisal of such materials with members of the public (cf. Pidgeon and Fischoff 2011).

\subsection{Study limitations}

Our findings may have limited generalisability beyond the UK, a country where weather has a distinct cultural significance (Harley 2003) and which experiences cold weather extremes only sporadically. A further caveat concerns our assumption of the direction of causality from climate change scepticism to weather interpretations. Our modelling of the data is based on theory-specifically that general worldviews underpin attitudes towards climate change, and that these pre-existing attitudes influence people's interpretation of ambiguous evidence. However, we cannot be certain in the present study that, for some people, direct experience of extreme cold weather may itself have been salient enough to lead to climate change scepticism. It would thus be desirable for future studies to examine in a longitudinal manner the effects of climate change scepticism upon evidence interpretation-particularly given that previous research has shown that situation-dependent cues such as a person's perceived state of physical warmth can affect belief in climate change (Risen and Critcher 2011; Joireman et al. 2010) and that the interpretation of weather events in the context of climate change may vary as a function of a person's level of engagement with the issue (cf. Myers et al. 2013).

In the case of items used to gauge people's interpretation of cold weather events in the context of climate change, it should be noted that a respondent's disagreement with the statements provided could be taken to mean one of two things-either the holding of an opposing viewpoint or a rejection of (cold) weather as a form of evidence. For example, in the case of disagreement with the item 'The cold winter which occurred during late 2010, suggests that climate change may not be happening', this could be taken to mean either that the cold winter points instead to the reality of climate change, or that it provides no evidence either way.

We find a relatively large proportion of respondents attribute cold weather events to climate change, however the extent to which this might occur spontaneously outside of a survey setting is not fully answered by the present study. The links made by people between their experience of the weather and the physical reality of climate change may also at times be ambivalent and/or contradictory, as in other areas of environmental psychology (Castro et al. 2009). In addition it should be noted that, as with all survey studies using self-report measures, people's views on the meaning of weather events may be subject to bias in recall. More deliberative research with members of the public would therefore be useful to further clarify 
whether and how cold weather-and extreme weather more generally-is coming to be interpreted in the context of climate change.

Acknowledgments Catherine Cherry carried out the coding of survey items and media articles for this study together with the first author; she also provided helpful insights into the interpretation of respondents' comments and media articles. The authors thank Wouter Poortinga, Alexa Spence, and Adam Corner for comments on an earlier draft of the manuscript. We thank three anonymous reviewers for comments and suggestions which improved a number of aspects of the study. Climate change scepticism measures draw additionally on the work of Lorraine Whitmarsh. The research has been supported by a grant from the Economic and Social Research Council (RES-066-27-0013) and by the Climate Change Consortium of Wales.

Open Access This article is distributed under the terms of the Creative Commons Attribution License which permits any use, distribution, and reproduction in any medium, provided the original author(s) and the source are credited.

\section{References}

Akerlof K, Maibach EW, Fitzgerald D, Cedeno AY, Neuman A (2013) Do people "personally experience" global warming, and if so how, and does it matter? Glob Environ Chang 23(1):81-91

Bickerstaff K, Walker G (2001) Public understandings of air pollution: the 'localisation' of environmental risk. Glob Environ Chang 11:133-145

Blunden J, Arndt DS, Baringer MO (2011) State of the climate in 2010. Bull Am Meteorol Soc 92:S1-S236

Borick CP, Rabe BG (2010) A reason to believe: examining the factors that determine individual views on global warming. Soc Sci Q 91:777-800

Borick CP, Rabe BG (2012) Belief in global warming on the rebound: National survey of American public opinion on climate change. Issues in Governance Studies 44. http://www.brookings.edu/ $/$ media/research/files/papers/ 2012/2/climate\%20change\%20rabe\%20borick/02_climate_change_rabe_borick.pdf. Accessed 17 Sep 2013

Bostrom A, Lashof D (2007) Weather it's climate change? In: Moser SC, Dilling L (eds) Communicating a climate for change. Cambridge University Press, Cambridge

Brick JM (2011) The future of survey sampling. Public Opin Q 75(5):872-888

Capstick SB (2012) Climate change discourses in use by the UK public: commonalities and variations over a fifteen year period. Doctoral thesis, Cardiff University. http://orca.cf.ac.uk/24182/. Accessed 17 Sep 2013

Carvalho A (2010) Media(ted) discourses and climate change: a focus on political subjectivity and (dis)engagement. WIREs Clim Change 1(2):172-179

Castro P, Garrido M, Reis E, Menezes J (2009) Ambivalence and conservation behaviour: an exploratory study on the recycling of metal cans. J Environ Psychol 29(1):24-33

Cattiaux J, Vautard R, Cassou C, Yiou P, Masson-Delmotte V, Codron F (2010) Winter 2010 in Europe: a cold extreme in a warming climate. Geophys Res Lett 37, L20704

Corner A, Whitmarsh L, Xenias D (2012) Uncertainty, scepticism and attitudes towards climate change: biased assimilation and attitude polarisation. Clim Chang 114:463-478

Coumou D, Rahmstorf S (2012) A decade of weather extremes. Nat Clim Chang 2:491-496

Defra (2012) Summary of the key finding from the UK climate change risk assessment 2012. http://www.defra. gov.uk/sac/files/SAC1215-CCRA-Paper-Annex-1-Key-Findings.pdf. Accessed 17 Sep 2013

Goebbert K, Jenkins-Smith HC, Klockow K, Nowlin MC, Silva CL (2012) Weather, climate, and worldviews: the sources and consequences of public perceptions of changes in local weather patterns. Weather Clim Soc 4(2):132-144

Guirguis K, Gershunov A, Schwartz R, Bennett S (2011) Recent warm and cold daily winter temperature extremes in the Northern Hemisphere. Geophys Res Lett 38, L17701

Harley TA (2003) Nice weather for the time of year: The British obsession with the weather. In: Strauss S, Orlove B (eds) Weather, climate, culture. Berg, New York, pp 103-120

Hayes AF (2013) An introduction to mediation, moderation, and conditional process analysis: A regressionbased approach. Guilford Press, New York

Horlick-Jones T, Walls J, Kitzinger J (2007) Bricolage in action: learning about, making sense of, and discussing, issues about genetically modified crops and food. Health Risk Soc 9:83-103

Howe PD, Markowitz EM, Ming Lee T, Ko CY, Leiserowitz A (2013) Global perceptions of local temperature change. Nat Clim Chang 3:352-356 
Joireman J, Barnes Truelove H, Duell B (2010) Effect of outdoor temperature, heat primes and anchoring on belief in global warming. J Environ Psychol 30:358-367

Knight E (2012) Beyond the obvious. RSA Journal Autumn: 36-40. http://www.thersa.org/fellowship/journal/ archive/autumn-2012/features/beyond-the-obvious. Accessed 17 Sep 2013

Kunda Z (1990) The case for motivated reasoning. Psychol Bull 3:480-498

Leiserowitz A, Maibach EW, Roser-Renouf C, Smith N, Dawson E (2010) Climategate, Public Opinion and the Loss of Trust. Yale Project on Climate Change Communication Working Paper. http://environment.yale.edu/ climate/files/Climategate_Opinion_and_Loss_of_Trust_1.pdf. Accessed 17 Sep 2013

Leiserowitz A, Maibach E, Roser-Renouf C, Hmielowski JD (2012) Global warming's six americas, March 2012 \& November 2011. Yale Project on Climate Change Communication, Yale University. http://environment. yale.edu/climate/files/Six-Americas-March-2012.pdf. Accessed 17 Sep 2013

Li Y, Johnson EJ, Zaval L (2011) Local warming: daily variation in temperature affects beliefs and concern about climate change. Psychol Sci 22:454-459

Lord CG, Taylor CA (2009) Biased assimilation: effects of assumptions and expectations on the interpretation of new evidence. Soc Personal Psychol Compass 3:827-841

Lorenzoni I, Pidgeon NF (2006) Public views on climate change: European and USA perspectives. Clim Chang 77:73-95

Lorenzoni I, Leiserowitz A, Doria M, Poortinga W, Pidgeon N (2006) Cross national comparisons of image associations with "global warming" and "climate change" among laypeople in the United States of America and Great Britain. J Risk Res 9(3):265-281

Matthes J, Kohring M (2008) The content analysis of media frames: toward improving reliability and validity. J Commun 58(2):258-279

Moser SC, Dilling L (2011) Communicating climate change: Closing the science-action gap. In: Dryzek J, Norgaard RB, Schlosberg D (eds) The oxford handbook of climate change and society. Oxford University Press, Oxford, pp 161-176

Myers T, Maibach EW, Roser-Renouf C, Akerlof K, Leiserowitz A (2013) The relationship between personal experience and belief in the reality of global warming. Nat Clim Chang 3:343-347

Overland JE, Wood KR, Wang M (2011) Warm Arctic - cold continents: climate impacts of the newly open Arctic Sea. Polar Res 30:15787

Perkins S (2010) Atmospheric science: the cold facts. Nat Clim Chang. doi:10.1038/nclimate1008

Pidgeon NF (2012) Public understanding of, and attitudes to, climate change: UK and international perspectives and policy. Clim Policy 12:S85-S106

Pidgeon NF, Fischoff B (2011) The role of social and decision sciences in communicating uncertain climate risks. Nat Clim Chang 1:35-41

Poortinga W, Spence A, Whitmarsh L, Capstick SB, Pidgeon NF (2011) Uncertain climate: an investigation into public scepticism about anthropogenic climate change. Glob Environ Chang 21:1015-1024

Rahmstorf S (2004) The climate sceptics. Potsdam: Potsdam Institute for Climate Impact Research. http://www. pik-potsdam.de/ stefan/Publications/Other/rahmstorf_climate_sceptics_2004.pdf. Accessed 17 Sep 2013

Reynolds T, Bostrom A, Read D, Morgan M (2010) Now what do people know about global climate change? Survey studies of educated laypeople. Risk Anal 30(10):1520-1538

Rippl S (2002) Cultural theory and risk perception: a proposal for a better measurement. J Risk Res 5:147-165

Risen JL, Critcher CR (2011) Visceral fit: while in a visceral state, associated states of the world seem more likely. J Pers Soc Psychol 100(5):777-793

Shuckburgh E, Robison R, Pidgeon N (2012) Climate science, the public and the news media. Living with environmental change. http://www.lwec.org.uk/sites/default/files/LWEC_climate_science_web.pdf. Accessed 17 Sep 2013

Smith N, Joffe H (2013) How the public engages with global warming: a social representations approach. Public Underst Sci 22(1):16-32

Smith N, Leiserowitz A (2012) The rise of global warming skepticism: exploring affective image associations in the United States over time. Risk Anal 32:1021-1032

Spence A, Poortinga W, Butler C, Pidgeon NF (2011) Perceptions of climate change and willingness to save energy related to flood experience. Nat Clim Chang 1:46-49

Spence A, Poortinga W, Pidgeon NF (2012) The psychological distance of climate change. Risk Anal 32(6):957-972

Steg L, Sievers I (2000) Cultural theory and individual perceptions of environmental risks. Environ Behav 32:250-269

Thompson M (2003) Cultural theory, climate change and clumsiness. Econ Polit Wkly 38(48):5107-5112

Trenberth KE (2012) Framing the way to relate climate extremes to climate change. Clim Chang 115:283-290

Whitmarsh L (2009) What's in a name? Commonalities and differences in public understanding of 'climate change' and 'global warming'. Public Underst Sci 18:401-420

Whitmarsh L (2011) Scepticism and uncertainty about climate change: dimensions, determinants and change over time. Glob Environ Chang 21:690-700

Wildavsky A, Dake K (1990) Theories of risk perception: who fears what and why? Daedalus 119:41-60 